\title{
Molecular Characterization of Fusarium Wilt Resistant and Susceptible Safflower (Carthamus tinctorius L.) Genotypes
}

\author{
S.S. Shende* and D.H. Waghmare \\ Department of Plant Biotechnology, VilasraoDeshmukh College of Agricultural Biotechnology, \\ V.N.M.K.V., Latur (M.S.) India, Pin-413 512 \\ *Corresponding author
}

\author{
A B S T R A C T
}

Keywords

Safflower,

Fusarium wilt,

Genetic diversity, RAPD, SSR.

Article Info

Accepted:

10 July 2017

Available Online:

10 September 2017
Safflower (Carthamus tinctorius L.) is an oilseed crop that is valued as a source of high quality vegetable oil. The present study was carried out with the objective of evaluation of genetic diversity among 11 Fusarium wilt resistance and 5 susceptible safflower genotypes by using RAPD and SSR markers.241 RAPD primer as well as 17 SSR polymorphic primers were used in this study. Analysis diversity showed significant variation in genotypes for the Fusarium wilt disease-related traits. Based on RAPD markers, a total of 1444 bands were amplified and 885 bands $(6076 \%)$ of these were polymorphic and SSR yielded a total of 20 scorable bands and 19 bands (97.06\%) were polymorphic. A logical similarity between the genotype clusters based on molecular data with their resistance or susceptibility to Fusarium wilt was observed.PIC for RAPD markers ranged between 0.500.92 with an average of 0.80 and for SSR markers ranged between 0.12-0.96 with an average of 0.63 . Therefore, from the present study, it can be proved that RAPD and SSR markers can detect high polymorphism and are very useful in studying variation among different safflower genotypes.

\section{Introduction}

Safflower (Carthamus tinctorius L.) belongs to the family Asteraceae. It is one of the remarkable oldest domesticated crops (Hamdan et al., 2011). It is cultivated in some regions of Europe, Australia, Asia, and the Americas to produce high quality vegetable and industrial oil. Nowadays, it is cultivated mainly for its seed, which is used as source of edible oil and as birdseed (Dajue and Mundel, 1996). In the last few years, the safflower has been used as a biofuel, pharmaceutical production (McPherson et al., 2004) and particular oil types (Velasco and FernandezMartinez, 2004). Thereby, the interest in this crop has been increasing by both private and public sectors. Recent and future investigations about safflower may lead to the growth of this crop as important oilseed crop (Nabloussi and Boujghagh, 2006).

Biochemical, morphological and molecular markers are exploited to evaluate plant genetic diversity. During the past decades, molecular breeding, which has involved both markers assisted selection and genetic engineering, has witnessed significant innovations and advances ( $\mathrm{Xu}$ et al., 2012). Among various genetic markers, it is very 
important to identify, characterize and select the most appropriate ones for effective molecular studies. The most useful molecular markers are Inter Simple Sequence Repeats (ISSR), Random Amplified Polymorphic DNA (RAPD). Simple Sequence Repeats (SSR) and Amplified Fragment Length Polymorphism (AFLP) (Kumari et al., 2013).

Different molecular markers including RAPD (Sehgal and Raina, 2005; Ravikumar et al., 2008; Mahasi et al., 2009), AFLP (Zhang et al., 2006), ISSR (Yang et al., 2007; Golkar et al., 2011), and EST-SSR (Chapman et al., 2009; Mayerhofer et al., 2009; Barati and Arzani, 2012) have been used for evaluating genetic diversity in safflower. However, safflower has an enormous variability and several traits that could be genotyped via the available molecular marker systems (Sujatha, 2008). The markers reveal genetic relationship and distinctiveness among cultivars of a crop. The knowledge of diversity pattern will allow breeders to understand evolutionary relationship among accessions, to sample germplasm in a more systematic fashion. The genetic relationship and distinctiveness obtained for a cultivar facilitates selection of less related germplasm for intercrossing. This intercrossing ensures sustainable breeding programme in future. The knowledge of diversity also helps to develop strategies to incorporate useful diversity in breeding programmes. Considering above facts, the present investigation was carried out with the objective of assessing genetic diversity in Fusarium wilt resistant and susceptible genotypes of safflower by using molecular markers.

\section{Materials and Methods}

\section{Plant material}

Eleven Fusarium wilt resistant and five susceptible safflower genotypes were collected from Directorate of Oilseeds Research (DOR), Hyderabad (A.P), AICRP on Safflower of Vasantrao Naik Marathwada Krishi Vidyapeeth (VNMKV), Parbhani and Nimbkar Agricultural Research Station (NARI), Phaltan (M.S)(Table 1).

\section{Isolation of genomic DNA of safflower genotypes}

The total genomic DNA was isolated from all sixteen safflower genotypes by CTAB method (Saghai-Maroof et al., 1984).

\section{RAPD analysis}

RAPD PCR amplifications were carried in a total volume of $20 \mu \mathrm{l}$ reaction containing 50ng of genomic DNA, 1XPCR buffer with $\mathrm{MgCl}_{2}$, $0.2 \mathrm{mM}$ of each dNTP, 2.5pmol primer and 1 unit of Taq DNA polymerase (Aristogene, Bengaluru). PCR tubes were placed in thermal cycler (Sensoquest, Germany) for amplification of the genomic DNA as per the standardized protocol:initial denaturation of 7 min at $94^{\circ} \mathrm{C}$, followed by 40 cycles of $1 \mathrm{~min}$ at $94^{\circ} \mathrm{C}, 1 \mathrm{~min}$ at $36^{\circ} \mathrm{C}, 2 \mathrm{~min}$ at $72^{\circ} \mathrm{C}$ with a final extension step at $72^{\circ} \mathrm{C}$ for $10 \mathrm{~min}$ and hold at $4^{\circ} \mathrm{C}$

\section{SSR analysis}

SSR PCR amplifications were carried in a total volume of $20 \mu \mathrm{l}$ reaction containing 50 ng of genomic DNA, 1X PCR buffer with $\mathrm{MgCl}_{2}, 0.05 \mathrm{mM}$ of each dNTP, $0.5 \mathrm{pmol}$ primer and 1 unit of Taq DNA polymerase (Aristogene, Bengaluru). PCR tubes were placed in thermal cycler (Sensoquest, Germany) for amplification of the genomic DNA as per the standardized protocol:initial denaturation of $5 \mathrm{~min}$ at $94^{\circ} \mathrm{C}$, followed by 35 cycles of $45 \mathrm{sec}$ at $94^{\circ} \mathrm{C}, 55 \mathrm{sec}$ at $\mathrm{T}^{*}(\mathrm{Opt}), 1$ min at $72^{\circ} \mathrm{C}$ with a final extension step at $72^{\circ} \mathrm{C}$ for $8 \mathrm{~min}$ and hold at $4^{\circ} \mathrm{C}$. Amplification products were separated by using $1.5 \%$ for RAPD and $2 \%$ for SSR 
agarose gel electrophoresis run for 1hour in 1xTAE buffer and stained with ethidium bromide. DNA bands were visualized and photographed in gel documentation system (AlphaImager HP, USA).

\section{Data scoring and analysis}

The amplified product of RAPD and SSR from agarose gel images were scored for presence (1), absence (0), missing and doubtful case was scored as 9. Band size was determined by comparison with 100bp and 1000bp DNA ladder (ThermoScientific, USA). Data analysis was performed using NTSYS-PC (Numerical Taxonomy System, Version 2.02) Rohlf, (2000). The SIMQUAL programme was used to calculate the Jaccard's coefficient. Dendrogram was constructed using unweighted pair group method for arithmetic mean (UPGMA) based on Jaccard's coefficient (Figs 2 and 4).

\section{Results and Discussion}

\section{RAPD analysis}

Total 241 RAPD primers were selected on the basis of consistency and reproducibility of bands. These primers yielded a total of 1444 scorable bands. Total 885 bands were found to be polymorphic with 60.76 percent polymorphism (Table 2). The highest number of bands (14) was obtained with primer OPC07 (Fig. 1) and OPD-18, while the lowest number (2) was obtained with primer OPJ-08. Primers OPA-20, OPC-06, OPD-05, OPD-09, OPD-16, OPD-17, OPF-18, OPG-03, OPG09, OPG-20, OPH-02, OPH-04, OPH-12, OPH-13, OPH-17, OPH-18, OPH-19, OPJ-08, OPO-15, OPP-10, Primer-139, UBC-229, UBC-513 and UBC-521showed maximum polymorphism i.e. $100 \%$, whereas primer OPD-02 showed minimum i.e. $12.50 \%$ polymorphism.Total amplified fragments 18211 with average 75 amplified fragments per primer were obtained. Minimum amplified fragments 24 by primer
OPC-12 and maximum 164 by primer OPC07.Size of bands amplified by primers was noted, the minimum size ranged 200-1000bp and maximum size ranged 750$3500 \mathrm{bp}$. Thecalculated PIC values of these polymorphic primers ranged from 0.50-0.92 with an average of 0.80 .

Similar results were obtained by Safavi et al. (2010) used 13 RAPD primers generating 74 amplified fragments in which 60 were polymorphic showing related polymorphism i.e. $81.08 \%$ and noticed 3-9 RAPD fragments generated per primer with an average of 6bands per primer in safflower. Mahasi et al., (2009) and Khan et al., (2009) found out 61 and 78 amplified fragments from 14 and 15 RAPD primers and noticed 1-10 and 3-16 RAPD fragments generated per primer with an average of 5.5and 9.5 bands in safflower, respectively. On safflower same work was reported by Amini et al., (2008), and Souframanien and Gopalakrishna (2004) by using 15 and 25 RAPD primers which produced total polymorphic 132 and 44 bands and calculated amplified products range from 3 to 9 through standard of 1.8 and 13 bands for each primer, respectively.

\section{Cluster analysis based on RAPD data}

The dendrogram obtained using RAPD data indicates five clusters. Cluster I contained maximum (5) genotypes viz., GMU-5016, PBNS-117, NARI-38, GMU-5080 and NARI6 all are resistant to Fusarium wilt with $82 \%$ similarity. Cluster II comprised of 2 genotypes viz. NARI-NH-1 and GMU-4965 at $84 \%$ similarity value (Fig. 3). Cluster III contains 4 resistant genotypes i.e. NARI-H15, GMU-5153, GMU-4546 and GMU-4925 with $83 \%$ similarity. All 5 susceptible genotypes clustered separately in 2 main clusters i.e. IV and V. Cluster IV contains 3 susceptible genotypes viz. NIRA, BHIMA and SSF-708 sharing $83.5 \%$ similarity. 
Table.1 List of safflower genotypes resistant and susceptible to Fusarium wilt

\begin{tabular}{|c|c|c|c|}
\hline $\begin{array}{l}\text { S. } \\
\text { No. }\end{array}$ & $\begin{array}{c}\text { Name of the } \\
\text { Safflower Genotype }\end{array}$ & $\begin{array}{l}\text { Resistant/ } \\
\text { Susceptible }\end{array}$ & Source of Collection \\
\hline 1 & GMU 5016 & Resistant & Directorate of Oilseeds Research, Hyderabad \\
\hline 2 & PBNS 117 & Resistant & $\begin{array}{c}\text { All India Coordinated Research Programme on } \\
\text { Safflower, V.N.M.K.V., Parbhani }\end{array}$ \\
\hline 3 & GMU 5080 & Resistant & Directorate of Oilseeds Research, Hyderabad \\
\hline 4 & NARI-6 & Resistant & $\begin{array}{c}\text { Nimbkar Agricultural Research Institute, } \\
\text { Phalthan }\end{array}$ \\
\hline 5 & NARI-38 & Resistant & $\begin{array}{c}\text { Nimbkar Agricultural Research Institute, } \\
\text { Phalthan }\end{array}$ \\
\hline 6 & NARI-H-15 & Resistant & $\begin{array}{c}\text { Nimbkar Agricultural Research Institute, } \\
\text { Phalthan }\end{array}$ \\
\hline 7 & NARI-NH-1 & Resistant & $\begin{array}{c}\text { Nimbkar Agricultural Research Institute, } \\
\text { Phalthan }\end{array}$ \\
\hline 8 & GMU-5153 & Resistant & Directorate of Oilseeds Research, Hyderabad \\
\hline 9 & GMU-4546 & Resistant & Directorate of Oilseeds Research, Hyderabad \\
\hline 10 & GMU-4925 & Resistant & Directorate of Oilseeds Research, Hyderabad \\
\hline 11 & GMU-4965 & Resistant & Directorate of Oilseeds Research, Hyderabad \\
\hline 12 & NIRA & Susceptible & $\begin{array}{c}\text { Nimbkar Agricultural Research Institute, } \\
\text { Phalthan }\end{array}$ \\
\hline 13 & BHIMA & Susceptible & $\begin{array}{c}\text { All India Coordinated Research Programme on } \\
\text { Safflower, V.N.M.K.V., Parbhani }\end{array}$ \\
\hline 14 & SSF-708 & Susceptible & $\begin{array}{c}\text { All India Coordinated Research Programme on } \\
\text { Safflower, V.N.M.K.V., Parbhani }\end{array}$ \\
\hline 15 & PBNS-40 & Susceptible & $\begin{array}{c}\text { All India Coordinated Research Programme on } \\
\text { Safflower, V.N.M.K.V., Parbhani }\end{array}$ \\
\hline 16 & PBNS-12 & Susceptible & $\begin{array}{c}\text { All India Coordinated Research Programme on } \\
\text { Safflower, V.N.M.K.V., Parbhani }\end{array}$ \\
\hline
\end{tabular}

Table.2 Characteristics of the amplification products obtained by using RAPD primers

\begin{tabular}{|c|c|c|c|c|c|c|c|c|c|}
\hline $\begin{array}{l}\text { S. } \\
\text { No. }\end{array}$ & Primer ID & Sequence & $\begin{array}{c}\text { Total } \\
\text { Bands }\end{array}$ & $\begin{array}{c}\text { Mono } \\
\text { morphic } \\
\text { bands }\end{array}$ & $\begin{array}{c}\text { Poly } \\
\text { morphic } \\
\text { bands }\end{array}$ & $\begin{array}{c}\text { Poly } \\
\text { morphic } \\
\%\end{array}$ & $\begin{array}{c}\text { No. of } \\
\text { amplified } \\
\text { fragments }\end{array}$ & $\begin{array}{c}\text { Size of } \\
\text { amplicons } \\
\text { (range in } \\
\text { bp) }\end{array}$ & PIC \\
\hline 1 & OPA-01 & CAGGCCCTTC & 7 & 1 & 6 & 85.71 & 100 & $300-2500$ & 0.86 \\
\hline 2 & OPA-02 & TGCCGAGCTG & 8 & 3 & 5 & 62.50 & 112 & $250-1000$ & 0.87 \\
\hline 3 & OPA-03 & AGTCAGCCAC & 9 & 4 & 5 & 55.56 & 113 & $250-2000$ & 0.87 \\
\hline 4 & OPA-04 & AATCGGGCTG & 6 & 2 & 4 & 66.67 & 68 & $200-1500$ & 0.81 \\
\hline 5 & OPA-05 & AGGGGTCTTG & 8 & 5 & 3 & 37.50 & 113 & $300-1500$ & 0.87 \\
\hline 6 & OPA-06 & GGTCCCTGAC & 7 & 1 & 6 & 85.71 & 100 & $300-2500$ & 0.85 \\
\hline
\end{tabular}




\begin{tabular}{|c|c|c|c|c|c|c|c|c|c|}
\hline 7 & OPA-07 & GAAACGGGTG & 8 & 2 & 6 & 75.00 & 107 & $240-2000$ & 0.87 \\
\hline 8 & OPA-08 & GTGACGTAGG & 4 & 2 & 2 & 50.00 & 45 & $300-1000$ & 0.69 \\
\hline 9 & OPA-09 & GGGTAACGCC & 6 & 5 & 1 & 16.67 & 85 & $200-2400$ & 0.82 \\
\hline 10 & OPA-10 & GTGATCGCAG & 4 & 1 & 3 & 75.00 & 41 & $250-2000$ & 0.68 \\
\hline 11 & OPA-11 & CAATCGCCGT & 4 & 3 & 1 & 25.00 & 57 & $250-1000$ & 0.74 \\
\hline 12 & OPA-12 & TCGGCGATAG & 7 & 4 & 3 & 42.86 & 102 & $200-1500$ & 0.86 \\
\hline 13 & OPA-13 & CAGCACCCAC & 5 & 2 & 3 & 60.00 & 67 & $300-1500$ & 0.78 \\
\hline 14 & OPA-14 & TCTGTGCTGG & 5 & 1 & 4 & 80.00 & 70 & $300-2500$ & 0.8 \\
\hline 15 & OPA-15 & TTCCGAACCC & 6 & 1 & 5 & 83.33 & 90 & $300-1000$ & 0.83 \\
\hline 16 & OPA-16 & AGCCAGCGAA & 5 & 1 & 4 & 80.00 & 62 & $750-3000$ & 0.78 \\
\hline 17 & OPA-17 & GACCGCTTGT & 9 & 3 & 6 & 66.67 & 86 & $250-2000$ & 0.85 \\
\hline 18 & OPA-18 & AGGTGACCGT & 9 & 1 & 8 & 88.89 & 78 & $300-2500$ & 0.85 \\
\hline 19 & OPA-19 & CAAACGTCGG & 8 & 3 & 5 & 62.50 & 109 & $300-1000$ & 0.87 \\
\hline 20 & OPA-20 & GTTGCGATCC & 10 & 0 & 10 & 100.00 & 68 & $250-2000$ & 0.88 \\
\hline 21 & OPAB-02 & GGAAACCCCT & 6 & 2 & 4 & 66.67 & 85 & $200-1500$ & 0.83 \\
\hline 22 & OPAB-03 & TGGCGCACAC & 5 & 3 & 2 & 40.00 & 71 & $300-1500$ & 0.79 \\
\hline 23 & OPAB-04 & GGCACGCGTT & 5 & 3 & 2 & 40.00 & 77 & $300-2500$ & 0.8 \\
\hline 24 & OPAB-05 & CCCGAAGCGA & 8 & 3 & 5 & 62.50 & 103 & $300-1000$ & 0.86 \\
\hline 25 & OPAB-06 & GTGGCTTGGA & 4 & 3 & 1 & 25.00 & 63 & $500-2000$ & 0.75 \\
\hline 26 & OPAB-07 & GTAAACCGCC & 6 & 4 & 2 & 33.33 & 77 & $400-1700$ & 0.81 \\
\hline 27 & OPAC-09 & AGAGCGTACC & 5 & 4 & 1 & 20.00 & 79 & $200-1500$ & 0.8 \\
\hline 28 & OPAC-10 & AGCAGCGAGG & 13 & 3 & 10 & 76.92 & 143 & $300-2500$ & 0.91 \\
\hline 29 & OPAI-11 & ACGGCGATGA & 5 & 3 & 2 & 40.00 & 68 & $600-4000$ & 0.78 \\
\hline 30 & OPAK-05 & GATGGCAGTC & 7 & 3 & 4 & 57.14 & 80 & $400-2500$ & 0.83 \\
\hline 31 & OPAZ-01 & TCGGATCCGT & 7 & 5 & 2 & 28.57 & 103 & $300-1000$ & 0.85 \\
\hline 32 & OPAZ-02 & CCTGAACGGA & 6 & 4 & 2 & 33.33 & 78 & $500-2000$ & 0.81 \\
\hline 33 & OPAZ-03 & GGCTGTGTGG & 5 & 3 & 2 & 40.00 & 59 & $400-1700$ & 0.76 \\
\hline 34 & OPAZ-04 & CCAGCCTCAG & 4 & 2 & 2 & 50.00 & 46 & $400-2500$ & 0.71 \\
\hline 35 & OPAZ-07 & CACGAGTCTC & 6 & 1 & 5 & 83.33 & 83 & $200-2000$ & 0.83 \\
\hline 36 & OPB-01 & GTTTCGCTCC & 7 & 2 & 5 & 71.43 & 79 & $300-2500$ & 0.83 \\
\hline 37 & OPB-02 & TGATCCCTGG & 8 & 6 & 2 & 25.00 & 124 & $400-2300$ & 0.87 \\
\hline 38 & OPB-03 & CATCCCCCTG & 6 & 5 & 1 & 16.67 & 85 & $240-2500$ & 0.82 \\
\hline 39 & OPB-04 & GGACTGGAGT & 4 & 1 & 3 & 75.00 & 55 & $750-3500$ & 0.75 \\
\hline 40 & OPB-05 & TGCGCCCTTC & 5 & 4 & 1 & 20.00 & 78 & $250-2000$ & 0.8 \\
\hline 41 & OPB-06 & TGCTCTGCCC & 7 & 3 & 4 & 57.14 & 90 & $300-2500$ & 0.85 \\
\hline
\end{tabular}




\begin{tabular}{|c|c|c|c|c|c|c|c|c|c|}
\hline 42 & OPB-07 & GGTGACGCAG & 5 & 2 & 3 & 60.00 & 64 & $300-1000$ & 0.79 \\
\hline 43 & OPB-08 & GTCCACACGG & 9 & 5 & 4 & 44.44 & 120 & $240-2000$ & 0.88 \\
\hline 44 & OPB-09 & TGGGGGACTC & 8 & 4 & 4 & 50.00 & 93 & $300-1500$ & 0.85 \\
\hline 45 & OPB-10 & CTGCTGGGAC & 4 & 1 & 3 & 75.00 & 54 & $200-1500$ & 0.75 \\
\hline 46 & OPB-11 & GTAGACCCGT & 5 & 2 & 3 & 60.00 & 71 & $300-1000$ & 0.8 \\
\hline 47 & OPB-12 & CCTTGACGCA & 6 & 2 & 4 & 66.67 & 81 & $200-2400$ & 0.83 \\
\hline 48 & OPB-13 & TTCCCCCGCT & 6 & 3 & 3 & 50.00 & 79 & $250-2000$ & 0.8 \\
\hline 49 & OPB-14 & TCCGCTCTGG & 8 & 3 & 5 & 62.50 & 97 & $300-2500$ & 0.86 \\
\hline 50 & OPB-15 & GGAGGGTGTT & 6 & 1 & 5 & 83.33 & 64 & $300-1500$ & 0.81 \\
\hline 51 & OPB-16 & TTTGCCCGGA & 5 & 3 & 2 & 40.00 & 76 & $200-2000$ & 0.8 \\
\hline 52 & OPB-17 & AGGGAACGAG & 7 & 3 & 4 & 57.14 & 89 & $300-2500$ & 0.85 \\
\hline 53 & OPB-18 & CCACAGCAGT & 4 & 2 & 2 & 50.00 & 51 & $300-1500$ & 0.71 \\
\hline 54 & OPB-19 & ACCCCCGAAG & 7 & 6 & 1 & 14.29 & 110 & $200-1500$ & 0.86 \\
\hline 55 & OPB-20 & GGACCCTTAC & 9 & 2 & 7 & 77.78 & 78 & $300-1000$ & 0.85 \\
\hline 56 & OPBA-18 & CTCGGATGTC & 5 & 1 & 4 & 80.00 & 58 & $200-2400$ & 0.78 \\
\hline 57 & OPBH-02 & GTAAGCCGAG & 8 & 2 & 6 & 75.00 & 114 & $250-2000$ & 0.87 \\
\hline 58 & OPC-01 & TTCGAGCCAG & 5 & 1 & 4 & 80.00 & 59 & $250-1000$ & 0.78 \\
\hline 59 & OPC-02 & GTGAGGCGTC & 5 & 1 & 4 & 80.00 & 62 & $200-1500$ & 0.78 \\
\hline 60 & OPC-03 & GGGGGTCTTT & 5 & 2 & 3 & 60.00 & 67 & $300-1500$ & 0.78 \\
\hline 61 & OPC-04 & CCGCATCTAC & 6 & 3 & 3 & 50.00 & 78 & $300-2500$ & 0.82 \\
\hline 62 & OPC-05 & GATGACCGCC & 5 & 1 & 4 & 80.00 & 37 & $300-1500$ & 0.71 \\
\hline 63 & OPC-06 & GAACGGACTC & 7 & 0 & 7 & 100.00 & 79 & $300-1000$ & 0.84 \\
\hline 64 & OPC-07 & GTCCCGACGA & 14 & 4 & 10 & 71.43 & 164 & $200-2400$ & 0.92 \\
\hline 65 & OPC-08 & TGGACCGGTG & 6 & 3 & 3 & 50.00 & 82 & $300-1500$ & 0.82 \\
\hline 66 & OPC-09 & CTCACCGTCC & 6 & 2 & 4 & 66.67 & 74 & $200-1500$ & 0.82 \\
\hline 67 & OPC-10 & TGTCTGGGTG & 4 & 1 & 3 & 75.00 & 44 & $300-1000$ & 0.72 \\
\hline 68 & OPC-11 & AAAGCTGCGG & 7 & 5 & 2 & 28.57 & 95 & $200-2400$ & 0.84 \\
\hline 69 & OPC-12 & TGTCATCCCC & 4 & 1 & 3 & 75.00 & 24 & $250-2000$ & 0.52 \\
\hline 70 & OPC-13 & AAGCCTCGTC & 5 & 1 & 4 & 80.00 & 64 & $250-1000$ & 0.79 \\
\hline 71 & OPC-14 & TGCGTGCTTG & 5 & 2 & 3 & 60.00 & 70 & $200-1500$ & 0.8 \\
\hline 72 & OPC-15 & GACGGATCAG & 7 & 1 & 6 & 85.71 & 53 & $300-1300$ & 0.79 \\
\hline 73 & OPC-16 & CACACTCCAG & 5 & 1 & 4 & 80.00 & 54 & $250-1000$ & 0.76 \\
\hline 74 & OPC-17 & TTCCCCCCAG & 4 & 2 & 2 & 50.00 & 62 & $200-1500$ & 0.75 \\
\hline 75 & OPC-18 & TGAGTGGGTG & 4 & 1 & 3 & 75.00 & 59 & $300-1500$ & 0.75 \\
\hline 76 & OPC-19 & GTTGCCAGCC & 7 & 2 & 5 & 71.43 & 103 & $300-2500$ & 0.86 \\
\hline
\end{tabular}




\begin{tabular}{|c|c|c|c|c|c|c|c|c|c|}
\hline 77 & OPC-20 & ACTTCGCCAC & 7 & 5 & 2 & 28.57 & 96 & $250-2000$ & 0.85 \\
\hline 78 & OPD-01 & ACCGCGAAGG & 7 & 6 & 1 & 14.29 & 110 & $300-1000$ & 0.86 \\
\hline 79 & OPD-02 & GGACCCAACC & 8 & 7 & 1 & 12.50 & 127 & $300-1500$ & 0.87 \\
\hline 80 & OPD-03 & GTCGCCGTCA & 6 & 3 & 3 & 50.00 & 72 & $200-1500$ & 0.81 \\
\hline 81 & OPD-04 & TCTGGTGAGG & 5 & 2 & 3 & 60.00 & 48 & $300-1000$ & 0.74 \\
\hline 82 & OPD-05 & TGAGCGGACA & 8 & 0 & 8 & 100.00 & 79 & $200-2400$ & 0.84 \\
\hline 83 & OPD-06 & ACCTGAACGG & 8 & 1 & 7 & 87.50 & 59 & $250-2000$ & 0.82 \\
\hline 84 & OPD-07 & TTGGCACGGG & 4 & 3 & 1 & 25.00 & 63 & $250-1000$ & 0.75 \\
\hline 85 & OPD-08 & GTGTGCCCCA & 5 & 2 & 3 & 60.00 & 44 & $200-1500$ & 0.71 \\
\hline 86 & OPD-09 & CTCTGGAGAC & 5 & 0 & 5 & 100.00 & 51 & $300-1500$ & 0.77 \\
\hline 87 & OPD-10 & GGTCTACACC & 6 & 1 & 5 & 83.33 & 63 & $500-2500$ & 0.78 \\
\hline 88 & OPD-11 & AGCGCCATTG & 3 & 2 & 1 & 33.33 & 47 & $200-2000$ & 0.67 \\
\hline 89 & OPD-12 & CACCGTATCC & 6 & 4 & 2 & 33.33 & 94 & $300-2500$ & 0.83 \\
\hline 90 & OPD-13 & GGGGTGACGA & 7 & 4 & 3 & 42.86 & 106 & $400-2300$ & 0.86 \\
\hline 91 & OPD-14 & CTTCCCCAAG & 5 & 1 & 4 & 80.00 & 42 & $200-1200$ & 0.73 \\
\hline 92 & OPD-15 & CATCCGTGCT & 4 & 2 & 2 & 50.00 & 61 & $200-1500$ & 0.75 \\
\hline 93 & OPD-16 & AGGGCGTAAG & 4 & 0 & 4 & 100.00 & 31 & $300-1500$ & 0.65 \\
\hline 94 & OPD-17 & TTTCCCACGG & 6 & 0 & 6 & 100.00 & 53 & $300-2500$ & 0.82 \\
\hline 95 & OPD-18 & GAGAGCCAAC & 14 & 5 & 9 & 64.29 & 130 & $250-2000$ & 0.91 \\
\hline 96 & OPD-19 & CTGGGGACTT & 7 & 4 & 3 & 42.86 & 108 & $300-1000$ & 0.86 \\
\hline 97 & OPD-20 & ACCCGGTCAC & 6 & 3 & 3 & 50.00 & 79 & $200-2400$ & 0.82 \\
\hline 98 & OPE-15 & ACGCACAACC & 5 & 3 & 2 & 40.00 & 61 & $250-2000$ & 0.77 \\
\hline 99 & OPF-01 & ACGGATCCTG & 3 & 1 & 2 & 66.67 & 46 & $250-1000$ & 0.67 \\
\hline 100 & OPF-02 & GAGGATCCCT & 4 & 3 & 1 & 25.00 & 53 & $200-1500$ & 0.72 \\
\hline 101 & OPF-03 & CCTGATCACC & 6 & 5 & 1 & 16.67 & 94 & $300-1500$ & 0.83 \\
\hline 102 & OPF-04 & GGTGATCAGG & 4 & 3 & 1 & 25.00 & 53 & $300-2500$ & 0.72 \\
\hline 103 & OPF-05 & CCGAATTCCC & 6 & 5 & 1 & 16.67 & 94 & $300-1000$ & 0.83 \\
\hline 104 & OPF-06 & GGGAATTCGG & 6 & 4 & 2 & 33.33 & 70 & $500-2000$ & 0.81 \\
\hline 105 & OPF-07 & CCGATATCCC & 4 & 1 & 3 & 75.00 & 56 & $400-1700$ & 0.75 \\
\hline 106 & OPF-08 & GGGATATCGG & 5 & 3 & 2 & 40.00 & 63 & $400-2500$ & 0.76 \\
\hline 107 & OPF-09 & CCAAGCTTCC & 6 & 3 & 3 & 50.00 & 64 & $200-2000$ & 0.79 \\
\hline 108 & OPF-10 & GGAAGCTTGG & 4 & 3 & 1 & 25.00 & 51 & $300-2500$ & 0.7 \\
\hline 109 & OPF-11 & TTGGTACCCC & 4 & 1 & 3 & 75.00 & 33 & $400-2300$ & 0.66 \\
\hline 110 & OPF-12 & ACGGTACCAG & 6 & 4 & 2 & 33.33 & 77 & $240-2500$ & 0.81 \\
\hline 111 & OPF-13 & GGCTGCAGAA & 6 & 4 & 2 & 33.33 & 76 & $750-3500$ & 0.81 \\
\hline
\end{tabular}




\begin{tabular}{|c|c|c|c|c|c|c|c|c|c|}
\hline 112 & OPF-14 & TGCTGCAGGT & 6 & 3 & 3 & 50.00 & 70 & $250-2000$ & 0.79 \\
\hline 113 & OPF-15 & CCAGTACTCC & 4 & 1 & 3 & 75.00 & 47 & $300-2500$ & 0.73 \\
\hline 114 & OPF-16 & GGAGTACTGG & 9 & 2 & 7 & 77.78 & 92 & $200-1500$ & 0.86 \\
\hline 115 & OPF-17 & AACCCGGGAA & 7 & 4 & 3 & 42.86 & 102 & $250-1000$ & 0.86 \\
\hline 116 & OPF-18 & TTCCCGGGTT & 4 & 0 & 4 & 100.00 & 59 & $250-1500$ & 0.75 \\
\hline 117 & OPF-19 & CCTCTAGACC & 6 & 4 & 2 & 33.33 & 77 & $240-2000$ & 0.81 \\
\hline 118 & OPF-20 & GGTCTAGAGG & 7 & 1 & 6 & 85.71 & 74 & $300-1500$ & 0.82 \\
\hline 119 & OPG-01 & CTACGGAGGA & 6 & 2 & 4 & 66.67 & 71 & $300-1500$ & 0.81 \\
\hline 120 & OPG-02 & GGCACTGAGG & 9 & 1 & 8 & 88.89 & 97 & $200-1500$ & 0.88 \\
\hline 121 & OPG-03 & GAGCCCTCCA & 4 & 0 & 4 & 100.00 & 52 & $300-1000$ & 0.74 \\
\hline 122 & OPG-04 & AGCGTGTCTG & 5 & 2 & 3 & 60.00 & 41 & $200-2400$ & 0.68 \\
\hline 123 & OPG-05 & CTGAGACGGA & 4 & 1 & 3 & 75.00 & 44 & $250-2000$ & 0.72 \\
\hline 124 & OPG-06 & GTGCCTAACC & 5 & 2 & 3 & 60.00 & 68 & $200-1500$ & 0.78 \\
\hline 125 & OPG-07 & GAACCTGCGG & 8 & 3 & 5 & 62.50 & 108 & $300-1500$ & 0.87 \\
\hline 126 & OPG-08 & TCACGTCCAC & 5 & 3 & 2 & 40.00 & 68 & $300-2500$ & 0.79 \\
\hline 127 & OPG-09 & CTGACGTCAC & 6 & 0 & 6 & 100.00 & 64 & $300-1000$ & 0.81 \\
\hline 128 & OPG-10 & AGGGCCGTCT & 6 & 3 & 3 & 50.00 & 82 & $500-2000$ & 0.82 \\
\hline 129 & OPG-11 & TGCCCGTCGT & 6 & 2 & 4 & 66.67 & 74 & $400-1700$ & 0.82 \\
\hline 130 & OPG-12 & CAGCTCACGA & 3 & 1 & 2 & 66.67 & 38 & $400-2500$ & 0.66 \\
\hline 131 & OPG-13 & CTCTCCGCCA & 5 & 1 & 4 & 80.00 & 40 & $200-2000$ & 0.73 \\
\hline 132 & OPG-14 & GGATGAGACC & 5 & 3 & 2 & 28.57 & 91 & $300-2500$ & 0.84 \\
\hline 133 & OPG-15 & ACTGGGACTC & 5 & 1 & 4 & 80.00 & 41 & $400-2300$ & 0.69 \\
\hline 134 & OPG-16 & AGCGTCCTCC & 6 & 2 & 4 & 66.67 & 75 & $240-2500$ & 0.82 \\
\hline 135 & OPG-17 & ACGACCGACA & 6 & 1 & 5 & 83.33 & 63 & $750-3500$ & 0.78 \\
\hline 136 & OPG-18 & GGCTCATGTG & 8 & 2 & 6 & 75.00 & 88 & $250-2000$ & 0.86 \\
\hline 137 & OPG-19 & GTCAGGGCAA & 7 & 6 & 1 & 14.29 & 111 & $300-2500$ & 0.86 \\
\hline 138 & OPG-20 & TCTCCCTCAG & 5 & 0 & 5 & 100.00 & 36 & $300-1000$ & 0.71 \\
\hline 139 & OPH-01 & GGTCGGAGAA & 5 & 2 & 3 & 60.00 & 52 & $400-2000$ & 0.76 \\
\hline 140 & OPH-02 & TCGGACGTGA & 8 & 0 & 8 & 100.00 & 57 & $300-1000$ & 0.81 \\
\hline 141 & OPH-03 & AGACGTCCAC & 5 & 3 & 2 & 40.00 & 69 & $300-2500$ & 0.78 \\
\hline 142 & OPH-04 & GGAAGTCGCC & 5 & 0 & 5 & 100.00 & 44 & $400-2300$ & 0.73 \\
\hline 143 & OPH-05 & AGTCGTCCCC & 4 & 3 & 1 & 25.00 & 62 & $240-2500$ & 0.75 \\
\hline 144 & OPH-06 & ACGCATCGCA & 5 & 2 & 3 & 60.00 & 57 & $750-3500$ & 0.76 \\
\hline 145 & OPH-07 & CTGCATCGTG & 8 & 1 & 7 & 87.50 & 84 & $250-1500$ & 0.87 \\
\hline 146 & OPH-08 & GAAACACCCC & 6 & 1 & 5 & 83.33 & 71 & $240-2000$ & 0.81 \\
\hline
\end{tabular}




\begin{tabular}{|c|c|c|c|c|c|c|c|c|c|}
\hline 147 & OPH-09 & TGTAGCTGGG & 8 & 3 & 5 & 62.50 & 121 & $300-1500$ & 0.87 \\
\hline 148 & OPH-10 & CCTACGTCAG & 6 & 2 & 4 & 66.67 & 88 & $200-1500$ & 0.83 \\
\hline 149 & OPH-11 & CTTCCGCAGT & 7 & 3 & 4 & 57.14 & 94 & $300-1000$ & 0.85 \\
\hline 150 & OPH-12 & ACGCGCATGT & 5 & 0 & 5 & 100.00 & 68 & $200-2400$ & 0.8 \\
\hline 151 & OPH-13 & GACGCCACAC & 6 & 0 & 6 & 100.00 & 80 & $250-2000$ & 0.86 \\
\hline 152 & OPH-14 & ACCAGGTTGG & 4 & 2 & 2 & 50.00 & 62 & $250-1000$ & 0.75 \\
\hline 153 & $\mathrm{OPH}-15$ & AATGGCGCAG & 6 & 2 & 4 & 66.67 & 87 & $200-1500$ & 0.83 \\
\hline 154 & OPH-16 & TCTCAGCTGG & 5 & 1 & 4 & 80.00 & 52 & $300-1500$ & 0.73 \\
\hline 155 & OPH-17 & САСТСТССТС & 6 & 0 & 6 & 100.00 & 80 & $300-2500$ & 0.83 \\
\hline 156 & OPH-18 & GAATCGGCCA & 5 & 0 & 5 & 100.00 & 62 & $300-1000$ & 0.78 \\
\hline 157 & OPH-19 & CTGACCAGCC & 5 & 0 & 5 & 100.00 & 72 & $500-2000$ & 0.8 \\
\hline 158 & OPH-20 & GGGAGACATC & 6 & 1 & 5 & 83.33 & 63 & $240-2000$ & 0.79 \\
\hline 159 & OPI-16 & TCTCCGCCCT & 8 & 1 & 7 & 87.50 & 70 & $200-1500$ & 0.83 \\
\hline 160 & OPJ-01 & CCCGGCATAA & 7 & 4 & 3 & 42.86 & 77 & $250-1000$ & 0.82 \\
\hline 161 & OPJ-02 & CCCGTTGGGA & 6 & 2 & 4 & 66.67 & 75 & $200-2400$ & 0.81 \\
\hline 162 & OPJ-03 & TCTCCGCTTG & 6 & 1 & 5 & 83.33 & 64 & $250-2000$ & 0.8 \\
\hline 163 & OPJ-04 & CCGAACACGG & 4 & 2 & 2 & 50.00 & 56 & $250-1000$ & 0.74 \\
\hline 164 & OPJ-05 & CTCCATGGGG & 7 & 2 & 5 & 71.43 & 94 & $200-1500$ & 0.85 \\
\hline 165 & OPJ-06 & TCGTTCCGCA & 5 & 3 & 2 & 40.00 & 78 & $300-1500$ & 0.8 \\
\hline 166 & OPJ-07 & CCTCTCGACA & 5 & 1 & 4 & 80.00 & 41 & $750-2000$ & 0.68 \\
\hline 167 & OPJ-08 & CATACCGTGG & 2 & 0 & 2 & 100.00 & 28 & $250-1500$ & 0.5 \\
\hline 168 & OPJ-09 & TGAGCCTCAC & 4 & 1 & 3 & 75.00 & 56 & $240-2000$ & 0.74 \\
\hline 169 & OPJ-10 & AAGCCCGAGG & 4 & 2 & 2 & 50.00 & 61 & $300-1500$ & 0.75 \\
\hline 170 & OPJ-11 & ACTCCTGCGA & 7 & 1 & 6 & 85.71 & 86 & $250-1300$ & 0.84 \\
\hline 171 & OPJ-12 & GTCCCGTGGT & 6 & 2 & 4 & 66.67 & 74 & $400-2500$ & 0.82 \\
\hline 172 & OPJ-13 & CCACACTACC & 5 & 3 & 2 & 40.00 & 65 & $200-2000$ & 0.78 \\
\hline 173 & OPJ-14 & CACCCGGATG & 9 & 5 & 4 & 44.44 & 127 & $300-2500$ & 0.88 \\
\hline 174 & OPJ-15 & TGTAGCAGGG & 5 & 2 & 3 & 60.00 & 71 & $400-2300$ & 0.8 \\
\hline 175 & OPJ-16 & CTGCTTAGGG & 6 & 2 & 4 & 66.67 & 76 & $240-2500$ & 0.82 \\
\hline 176 & OPJ-17 & ACGCCAGTTC & 6 & 3 & 3 & 50.00 & 56 & $750-3500$ & 0.75 \\
\hline 177 & OPJ-18 & TGGTCGCAGA & 4 & 2 & 2 & 50.00 & 56 & $250-2000$ & 0.73 \\
\hline 178 & OPJ-19 & GGACACCACT & 4 & 2 & 2 & 50.00 & 53 & $300-2500$ & 0.72 \\
\hline 179 & OPJ-20 & AAGCGGCCTC & 4 & 2 & 2 & 50.00 & 50 & $300-1000$ & 0.7 \\
\hline 180 & OPK-10 & GTGCAACGTG & 5 & 2 & 3 & 60.00 & 44 & $250-1000$ & 0.71 \\
\hline 181 & OPK-13 & GGTTGTACCC & 7 & 2 & 5 & 71.43 & 84 & $240-2000$ & 0.84 \\
\hline
\end{tabular}




\begin{tabular}{|c|c|c|c|c|c|c|c|c|c|}
\hline 182 & OPK-14 & CCCGCTACAC & 4 & 1 & 3 & 75.00 & 46 & $400-2500$ & 0.73 \\
\hline 183 & OPK-15 & CTCCTGCCAA & 11 & 4 & 7 & 63.64 & 145 & $300-1700$ & 0.9 \\
\hline 184 & OPK-16 & GAGCGTCGAA & 5 & 2 & 3 & 60.00 & 77 & $300-1000$ & 0.8 \\
\hline 185 & OPK-17 & CCCAGCTGTG & 4 & 1 & 3 & 75.00 & 57 & $200-2400$ & 0.75 \\
\hline 186 & OPK-18 & CCTAGTCGAG & 4 & 2 & 2 & 50.00 & 62 & $250-2000$ & 0.75 \\
\hline 187 & OPK-19 & CACAGGCGGA & 6 & 1 & 5 & 83.33 & 72 & $250-1000$ & 0.8 \\
\hline 188 & OPK-20 & GTGTCGCGAG & 7 & 3 & 4 & 57.14 & 97 & $200-1500$ & 0.85 \\
\hline 189 & OPM-20 & AGGTCTTGGG & 6 & 2 & 4 & 66.67 & 90 & $300-1500$ & 0.81 \\
\hline 190 & OPN-04 & GACCGACCCA & 6 & 3 & 3 & 50.00 & 82 & $300-2500$ & 0.82 \\
\hline 191 & OPO-09 & TCCCACGCAA & 6 & 1 & 5 & 83.33 & 76 & $300-1000$ & 0.82 \\
\hline 192 & OPO-15 & TGGCGTCCTT & 5 & 0 & 5 & 100.00 & 69 & $500-2000$ & 0.8 \\
\hline 193 & OPO-19 & GGTGCACGTT & 9 & 4 & 5 & 55.56 & 119 & $240-2500$ & 0.9 \\
\hline 194 & OPP-07 & GTCCATGCCA & 6 & 4 & 2 & 33.33 & 86 & $750-3500$ & 0.83 \\
\hline 195 & OPP-08 & ACATCGCCCA & 9 & 4 & 5 & 55.56 & 131 & $250-2000$ & 0.89 \\
\hline 196 & OPP-10 & TCCCGCCTAC & 8 & 0 & 8 & 100.00 & 107 & $300-2500$ & 0.87 \\
\hline 197 & OPP-11 & AACGCGTCGG & 7 & 4 & 3 & 42.86 & 86 & $300-1000$ & 0.83 \\
\hline 198 & OPP-13 & GGAGTGCCTC & 4 & 1 & 3 & 75.00 & 52 & $240-2000$ & 0.73 \\
\hline 199 & OPP-14 & CCAGCCGAAC & 6 & 4 & 2 & 33.33 & 81 & $240-2500$ & 0.82 \\
\hline 200 & OPQ-05 & CCGCGTCTTG & 7 & 3 & 4 & 57.14 & 86 & $750-3500$ & 0.83 \\
\hline 201 & OPT-08 & AACGGCGACA & 5 & 4 & 1 & 20.00 & 79 & $250-2000$ & 0.8 \\
\hline 202 & OPW-09 & GTGACCGAGT & 6 & 2 & 4 & 66.67 & 76 & $300-2500$ & 0.82 \\
\hline 203 & OPX-01 & CTGGGCACGA & 6 & 4 & 2 & 33.33 & 94 & $300-1000$ & 0.83 \\
\hline 204 & OPX-05 & ССТТТСССТС & 7 & 3 & 4 & 57.14 & 97 & $240-2000$ & 0.85 \\
\hline 205 & OPX-09 & GGTCTGGTTG & 4 & 2 & 2 & 50.00 & 54 & $240-2500$ & 0.73 \\
\hline 206 & OPX-16 & CTCTGTTCGG & 8 & 5 & 3 & 37.50 & 113 & $750-3500$ & 0.87 \\
\hline 207 & OPZ-10 & CCGACAAACC & 8 & 2 & 6 & 75.00 & 90 & $300-2000$ & 0.84 \\
\hline 208 & Primer-139 & GTTCGCTCC & 5 & 0 & 5 & 100.00 & 56 & $300-2500$ & 0.76 \\
\hline 209 & Primer-142 & AACGCGAAC & 6 & 4 & 2 & 33.33 & 88 & $400-2300$ & 0.83 \\
\hline 210 & RC-11 & TGACACCTC & 4 & 2 & 2 & 50.00 & 61 & $240-2500$ & 0.75 \\
\hline 211 & $\mathrm{RC}-14$ & CTGCTGAAG & 6 & 1 & 5 & 83.33 & 63 & $750-3500$ & 0.79 \\
\hline 212 & $\mathrm{RC}-15$ & CGGCTCGGT & 9 & 3 & 6 & 66.67 & 119 & $250-2000$ & 0.88 \\
\hline 213 & RC-16 & GAGCGTTGT & 7 & 2 & 5 & 71.43 & 76 & $300-2500$ & 0.83 \\
\hline 214 & RC-20 & ACCCGGACA & 6 & 2 & 4 & 66.67 & 79 & $300-1000$ & 0.82 \\
\hline 215 & RKAT-01 & CAGTGGTTCC & 6 & 3 & 3 & 50.00 & 93 & $300-2500$ & 0.83 \\
\hline 216 & RKAT-03 & GACTGGGAGG & 9 & 3 & 6 & 66.67 & 93 & $400-2300$ & 0.86 \\
\hline
\end{tabular}




\begin{tabular}{|c|c|c|c|c|c|c|c|c|c|}
\hline 217 & RKAT-04 & TTGCCTCGCC & 7 & 1 & 6 & 85.71 & 99 & $250-1000$ & 0.85 \\
\hline 218 & RKAT-09 & CCGTTAGCGT & 7 & 5 & 2 & 28.57 & 105 & $250-1500$ & 0.86 \\
\hline 219 & RKAT-13 & CTGGTGGAAG & 4 & 2 & 2 & 50.00 & 50 & $240-2000$ & 0.73 \\
\hline 220 & UBC-030 & CCGGCCTTAG & 6 & 5 & 1 & 16.67 & 93 & $300-1500$ & 0.83 \\
\hline 221 & UBC-120 & GAATTTCCCC & 9 & 6 & 3 & 33.33 & 138 & $200-1500$ & 0.89 \\
\hline 222 & UBC-125 & GCGGTTGAGG & 5 & 2 & 3 & 60.00 & 70 & $300-1000$ & 0.79 \\
\hline 223 & UBC-194 & AGGACGTGCC & 4 & 1 & 3 & 75.00 & 52 & $200-2400$ & 0.74 \\
\hline 224 & UBC-229 & CCACCCAGAG & 7 & 0 & 7 & 100.00 & 83 & $350-1700$ & 0.84 \\
\hline 225 & UBC-302 & CGGCCCACGT & 8 & 4 & 4 & 50.00 & 110 & $250-1000$ & 0.87 \\
\hline 226 & UBC-324 & ACAGGGAACG & 4 & 2 & 2 & 50.00 & 42 & $250-1500$ & 0.68 \\
\hline 227 & UBC-359 & AGGCAGACCT & 5 & 3 & 2 & 40.00 & 51 & $240-2000$ & 0.70 \\
\hline 228 & UBC-410 & CGTCACAGAG & 5 & 4 & 1 & 20.00 & 72 & $300-1500$ & 0.79 \\
\hline 229 & UBC-414 & AAGGCACCAG & 6 & 3 & 3 & 50.00 & 73 & $200-1500$ & 0.81 \\
\hline 230 & UBC-440 & CTGTCGAACC & 3 & 2 & 1 & 16.67 & 62 & $300-1000$ & 0.79 \\
\hline 231 & UBC-459 & GCGTCGAGGG & 6 & 2 & 4 & 80.00 & 74 & $200-2400$ & 0.8 \\
\hline 232 & UBC-497 & GCATAGTGCG & 6 & 2 & 4 & 66.67 & 70 & $250-2000$ & 0.81 \\
\hline 233 & UBC-513 & TCGGACGTAA & 6 & 0 & 6 & 100.00 & 69 & $200-2000$ & 0.8 \\
\hline 234 & UBC-521 & CTGAGACGCA & 4 & 0 & 4 & 100.00 & 46 & $250-1000$ & 0.72 \\
\hline 235 & UBC-841 & $\begin{array}{l}\text { GACACGACAC } \\
\text { GACACGACAC }\end{array}$ & 8 & 2 & 6 & 75.00 & 83 & $250-1000$ & 0.85 \\
\hline 236 & UBC-880 & $\begin{array}{l}\text { GGAGAGGAGA } \\
\text { GGAGAGGAGA }\end{array}$ & 6 & 2 & 4 & 66.67 & 64 & $200-1500$ & 0.79 \\
\hline 237 & Em12 & $\begin{array}{c}\text { GACTGCGTAC } \\
\text { GAATTCT }\end{array}$ & 5 & 3 & 2 & 40.00 & 73 & $300-1500$ & 0.79 \\
\hline 238 & Em5 & $\begin{array}{c}\text { GACTGCGTAC } \\
\text { GAATTAAC }\end{array}$ & 6 & 5 & 1 & 16.67 & 95 & $300-2500$ & 0.83 \\
\hline 239 & IR-74 & $\begin{array}{c}\text { CTCCTCСТCCТ } \\
\text { CСТC } \\
\end{array}$ & 6 & 2 & 4 & 66.67 & 84 & $300-1000$ & 0.83 \\
\hline 240 & IS-31 & $\begin{array}{l}\text { GCACACACAC } \\
\text { ACACACA }\end{array}$ & 5 & 3 & 2 & 40.00 & 77 & $500-2000$ & 0.8 \\
\hline 241 & Me8SCAR2 & $\begin{array}{c}\text { TGAGTCCAAA } \\
\text { CCGGACTACA } \\
\text { AG }\end{array}$ & 9 & 2 & 7 & 77.78 & 102 & $250-2500$ & 0.87 \\
\hline \multicolumn{3}{|c|}{ Total } & 1444 & 559 & 885 & -- & 18211 & -- & --- \\
\hline \multicolumn{3}{|c|}{ Average } & 6 & 2 & 3 & 60.76 & 75 & --- & 0.80 \\
\hline \multicolumn{3}{|c|}{ Minimum } & 2 & $\mathbf{0}$ & 1 & 12.50 & 24 & $200-1000$ & 0.50 \\
\hline \multicolumn{3}{|c|}{ Maximum } & 14 & 7 & 10 & 100 & 164 & $750-3500$ & 0.92 \\
\hline
\end{tabular}


Table.3 Similarity matrix among 16 safflower genotypes using RAPD and SSR data

\begin{tabular}{|c|c|c|c|c|c|c|c|c|c|c|c|c|c|c|c|c|c|c|c|}
\hline & $\sum_{i=1}^{\infty} \frac{0}{i}$ & 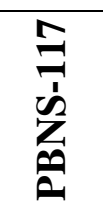 & $\sum_{0}^{\dot{2}} \stackrel{8}{\circ}$ & 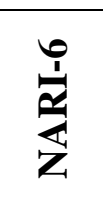 & 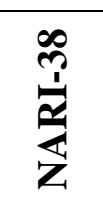 & 紊 & 交紊 & $\sum_{b}^{\infty} \frac{n}{n}$ & $\sum_{0}^{\dot{B}} \frac{0}{4}$ & 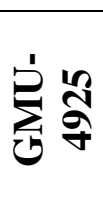 & $\sum_{b}^{j}$ & 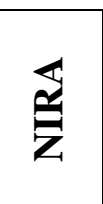 & 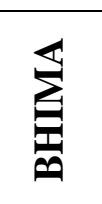 & 究 & 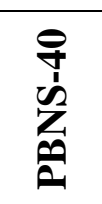 & 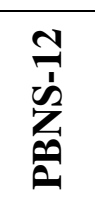 & 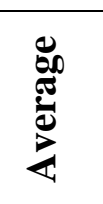 & 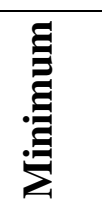 & 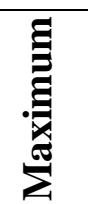 \\
\hline GMU-5016 & 1 & 0.65 & 0.70 & 0.70 & 0.75 & 0.70 & 0.75 & 0.55 & 0.60 & 0.70 & 0.55 & 0.55 & 0.40 & 0.50 & 0.35 & 0.40 & 0.62 & 0.35 & 0.75 \\
\hline PBNS-117 & 0.83 & 1 & 0.75 & 0.55 & 0.70 & 0.65 & 0.70 & 0.60 & 0.65 & 0.65 & 0.80 & 0.70 & 0.55 & 0.55 & 0.50 & 0.35 & 0.65 & 0.35 & 0.80 \\
\hline GMU-5080 & 0.81 & 0.85 & 1 & 0.60 & 0.95 & 0.70 & 0.75 & 0.55 & 0.60 & 0.80 & 0.75 & 0.75 & 0.60 & 0.60 & 0.25 & 0.40 & 0.67 & 0.25 & 0.95 \\
\hline NARI-6 & 0.79 & 0.85 & 0.84 & 1 & 0.55 & 0.70 & 0.75 & 0.75 & 0.60 & 0.60 & 0.65 & 0.65 & 0.60 & 0.50 & 0.55 & 0.50 & 0.64 & 0.50 & 0.75 \\
\hline NARI-38 & 0.81 & 0.86 & 0.82 & 0.81 & 1 & 0.75 & 0.80 & 0.60 & 0.65 & 0.85 & 0.70 & 0.70 & 0.55 & 0.65 & 0.20 & 0.35 & 0.67 & 0.20 & 0.95 \\
\hline NARI-H-15 & 0.81 & 0.82 & 0.81 & 0.80 & 0.83 & 1 & 0.85 & 0.75 & 0.80 & 0.70 & 0.55 & 0.65 & 0.50 & 0.60 & 0.35 & 0.50 & 0.67 & 0.35 & 0.85 \\
\hline -NH-1 & 0.75 & 0.74 & 0.75 & 0.74 & 0.74 & 0.81 & 1 & 0.70 & 0.75 & 0.85 & 0.60 & 0.70 & 0.55 & 0.65 & 0.30 & 0.45 & 0.70 & 0.30 & 0.85 \\
\hline MU-5153 & 0.81 & 0.80 & 0.81 & 0.80 & 0.80 & 0.84 & 0.79 & 1 & 0.85 & 0.65 & 0.80 & 0.70 & 0.65 & 0.65 & 0.50 & 0.35 & 0.67 & 0.35 & 0.85 \\
\hline MU-4546 & .78 & 0.79 & 0.79 & 0.80 & 0.79 & 0.86 & 0.80 & 0.87 & 1 & 0.70 & 0.65 & 0.65 & 0.50 & 0.60 & 0.45 & 0.30 & 0.65 & 0.30 & 0.85 \\
\hline GMU-4925 & 0.78 & 0.81 & 0.82 & 0.80 & 0.83 & 0.83 & 0.77 & 0.83 & 0.84 & 1 & 0.65 & 0.75 & 0.60 & 0.80 & 0.25 & 0.40 & 0.68 & 0.25 & 0.85 \\
\hline GMU-4965 & 0.77 & 0.79 & 0.79 & 0.77 & 0.78 & 0.84 & 0.83 & 0.81 & 0.84 & 0.83 & 1 & 0.80 & 0.75 & 0.65 & 0.50 & 0.35 & 0.67 & 0.35 & 0.80 \\
\hline NIRA & 0.77 & 0.77 & 0.77 & 0.78 & 0.80 & 0.79 & 0.75 & 0.81 & 0.81 & 0.81 & 0.78 & 1 & 0.85 & 0.85 & 0.40 & 0.55 & 0.70 & 0.40 & 0.85 \\
\hline BHIMA & 0.80 & 0.79 & 0.79 & 0.79 & 0.80 & 0.81 & 0.76 & 0.83 & 0.81 & 0.82 & 0.78 & 0.84 & & 0.80 & 0.55 & 0.60 & 0.63 & 0.40 & 0.85 \\
\hline SSF-708 & 0.76 & 0.79 & 0.76 & 0.77 & 0.79 & 0.82 & 0.76 & 0.77 & 0.79 & 0.78 & 0.79 & 0.80 & 0.84 & 1 & 0.45 & 0.60 & 0.65 & 0.45 & 0.85 \\
\hline PBNS-40 & 0.70 & 0.69 & 0.71 & 0.69 & 0.69 & 0.73 & 0.71 & 0.68 & 0.71 & 0.70 & 0.72 & 0.70 & 0.74 & 0.77 & 1 & 0.55 & 0.45 & 0.20 & 0.55 \\
\hline PBNS-12 & 0.73 & 0.72 & 0.73 & 0.73 & 0.71 & 0.74 & 0.71 & 0.72 & 0.72 & 0.71 & 0.73 & 0.72 & 0.76 & 0.79 & 0.83 & 1 & 0.48 & 0.30 & 0.60 \\
\hline & & 0.81 & & 0.80 & & 0.82 & & & 0.81 & & & 0.79 & & 0.80 & & 0.75 & & & \\
\hline & 0.70 & 0.69 & 0.71 & 0.69 & & 0.73 & 0.71 & 0.68 & 0.71 & 0.70 & 0.72 & 0.70 & 0.74 & 0.76 & 0.68 & 0.71 & & & \\
\hline Maximum & 0.83 & 0.86 & 0.85 & 0.85 & 0.86 & 0.86 & 0.83 & 0.87 & $\mathbf{0 . 8 7}$ & 0.84 & 0.84 & 0.84 & 0.84 & 0.84 & 0.83 & 0.83 & & & \\
\hline
\end{tabular}

Below diagonal RAPD similarity matrix, above diagonal SSR similarity matrix. 
Table.4 Characteristics of the amplification products obtained by using SSR primers

\begin{tabular}{|c|c|c|c|c|c|c|c|c|c|c|}
\hline $\begin{array}{l}\text { S. } \\
\text { No. }\end{array}$ & $\begin{array}{l}\text { Primer } \\
\text { ID }\end{array}$ & Sequence & $\begin{array}{l}\text { Anneali } \\
\text { ng Temp } \\
\left({ }^{\circ} \mathrm{C}\right)\end{array}$ & $\begin{array}{l}\text { Total } \\
\text { Bands }\end{array}$ & $\begin{array}{c}\text { Mono } \\
\text { morphic } \\
\text { bands }\end{array}$ & $\begin{array}{c}\text { Poly } \\
\text { morphic } \\
\text { bands }\end{array}$ & $\begin{array}{c}\text { Poly } \\
\text { morphic } \\
\%\end{array}$ & $\begin{array}{l}\text { No. of } \\
\text { amplified } \\
\text { fragments }\end{array}$ & $\begin{array}{c}\text { Size of } \\
\text { amplicons } \\
\text { (range in bp) }\end{array}$ & PIC \\
\hline 1 & $\begin{array}{c}\text { CaSTM } \\
\text { S-21 }\end{array}$ & $\begin{array}{l}\text { F-CTACAGTCTTTTGTTCTTCTAGCTT } \\
\text { R-ATATTTTTTAAGAGGCTTTTGGTAG }\end{array}$ & 55 & 1 & 0 & 1 & 100 & 11 & 150 & 0.53 \\
\hline 2 & LG-112 & $\begin{array}{c}\text { F- AAATGCACGCGATTTTCGCT } \\
\text { R- CGAAGCGAGTAAAGGGTCGT }\end{array}$ & 55 & 1 & 0 & 1 & 100 & 10 & 2000 & 0.61 \\
\hline 3 & LG-122 & $\begin{array}{l}\text { F-GGAATCGGAATCGGGGACTC } \\
\text { R-AGGTTTGACCTGCGTATCGG }\end{array}$ & 58 & 1 & 0 & 1 & 100 & 15 & 200 & 0.12 \\
\hline 4 & LG-123 & $\begin{array}{l}\text { F-GTTATGTGTTTGCGCGGTGT } \\
\text { R-AGGCAAGGAGGTTTGACCTG }\end{array}$ & 58 & 1 & 0 & 1 & 100 & 9 & 250 & 0.68 \\
\hline 5 & LG-124 & $\begin{array}{l}\text { F-GTGTTATGTGTTTGCGCGGT } \\
\text { R-GTATCGGCACTTCGACCCTT }\end{array}$ & 54 & 1 & 0 & 1 & 100 & 12 & 700 & 0.44 \\
\hline 6 & LG-125 & $\begin{array}{l}\text { F-TGTTATGTGTTTGCGCGGTG } \\
\text { R-CACTTCGACCCTTCAACCCT }\end{array}$ & 53 & 1 & 0 & 1 & 100 & 13 & 300 & 0.81 \\
\hline 7 & LG-132 & $\begin{array}{l}\text { F-TGAAATCCACCACTGCCCAT } \\
\text { R-GCCCCACCACAACTGAAACT }\end{array}$ & 60 & 1 & 0 & 1 & 100 & 8 & 200 & 0.44 \\
\hline 8 & LG-135 & $\begin{array}{l}\text { F-AAATCCACCACTGCCCATCT } \\
\text { R-CTGGCAAAAACGGTGCGAA }\end{array}$ & 58 & 1 & 0 & 1 & 100 & 12 & 300 & 0.75 \\
\hline 9 & LG-138 & $\begin{array}{l}\text { F-AAATCCACCACTGCCCATCTT } \\
\text { R-ACAGAAGTGGATGGACGTGT }\end{array}$ & 60 & 1 & 0 & 1 & 100 & 12 & 400 & 0.44 \\
\hline 10 & RGA-A & $\begin{array}{l}\text { F- GGGGGTGGGAAGACAACTAT } \\
\text { R- CTTCCTGGACCAAACCAATC }\end{array}$ & 60 & 1 & 0 & 1 & 100 & 8 & 300 & 0.75 \\
\hline 11 & RGA-C & $\begin{array}{l}\text { F- GGGTGGGGAAAACCACTCTA } \\
\text { R- CTGCTTGCTCTAAGGTTGCC }\end{array}$ & 52 & 1 & 0 & 1 & 100 & 14 & 100 & 0.23 \\
\hline 12 & RGA-D & $\begin{array}{c}\text { F- GCTCCCTGAACCAAACCAT } \\
\text { R- GGGGTCGGGAAGACAACTAT }\end{array}$ & 53 & 1 & 0 & 1 & 100 & 5 & 300 & 0.90 \\
\hline 13 & RGA-E & $\begin{array}{l}\text { F- GGGGTCGGGAAGACAACTAT } \\
\text { R- TCTGCTTCCTTTACCAAACCA }\end{array}$ & 57 & 1 & 0 & 1 & 100 & 5 & 250 & 0.90 \\
\hline 14 & RGA-F & $\begin{array}{l}\text { F- AATTTGATTTGAAAGGGTGGG } \\
\text { R- GGGGAAGCCATCACATTTTT }\end{array}$ & 48 & 2 & 0 & 2 & 100 & 14 & 500,300 & 0.96 \\
\hline 15 & RGA-G & $\begin{array}{l}\text { F- CCAATTTCCTGTGTACTGCC } \\
\text { R- GGGAGGCCATTAGCATACCT }\end{array}$ & 48 & 2 & 0 & 2 & 100 & 25 & 200,100 & 0.53 \\
\hline
\end{tabular}


Int.J.Curr.Microbiol.App.Sci (2017) 6(9): 3567-3584

\begin{tabular}{|c|c|c|c|c|c|c|c|c|c|c|}
\hline 16 & RGA-H & $\begin{array}{l}\text { F- GAAGACAGCCATAGCCGAAG } \\
\text { R- TTTGCTACCTGCACCAAACC }\end{array}$ & 53 & 2 & 1 & 1 & 50 & 25 & 500,300 & 0.68 \\
\hline 17 & TA-22 & $\begin{array}{l}\text { F-TCTCCAACCCTTTAGATTGA } \\
\text { R-TCGTGTTTACTGAATGTGGA }\end{array}$ & 51 & 1 & 0 & 1 & 100 & 14 & 800 & 0.87 \\
\hline \multicolumn{3}{|r|}{ Total } & --- & 20 & 1 & 19 & --- & 212 & --- & 10.64 \\
\hline \multicolumn{3}{|r|}{ Average } & 54.8 & 1.18 & 0.06 & 1.12 & 97.06 & 12.47 & 435.71 & 0.63 \\
\hline \multicolumn{3}{|r|}{ Minimum } & 48 & 1 & $\mathbf{0}$ & 1 & 50 & 5 & 100 & 0.12 \\
\hline \multicolumn{3}{|r|}{ Maximum } & 60 & 2 & 1 & 2 & 100 & 25 & 2000 & 0.96 \\
\hline
\end{tabular}

Fig.1 RAPD profile of 16 safflower genotypes by primer OPC-07

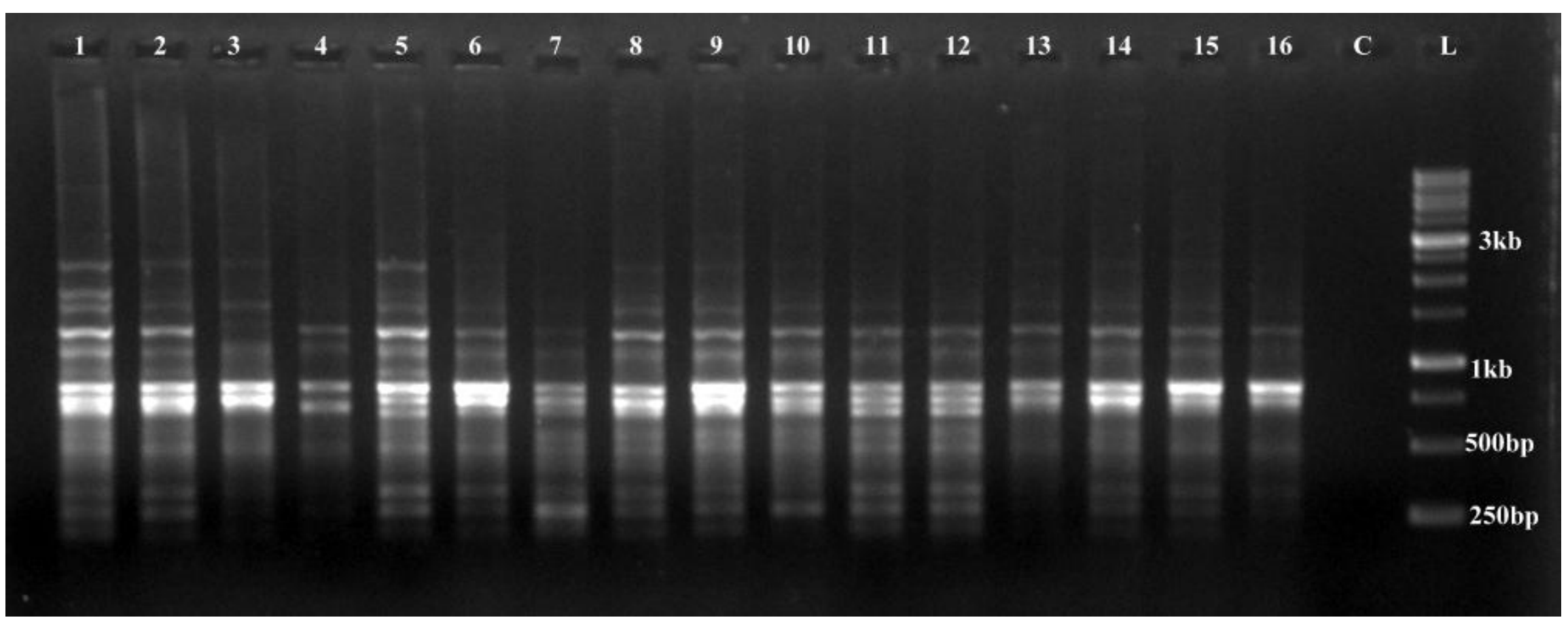


Fig.2UPGMA based dendrogram showing genetic relationship among 16 safflower genotypes based on RAPD analysis

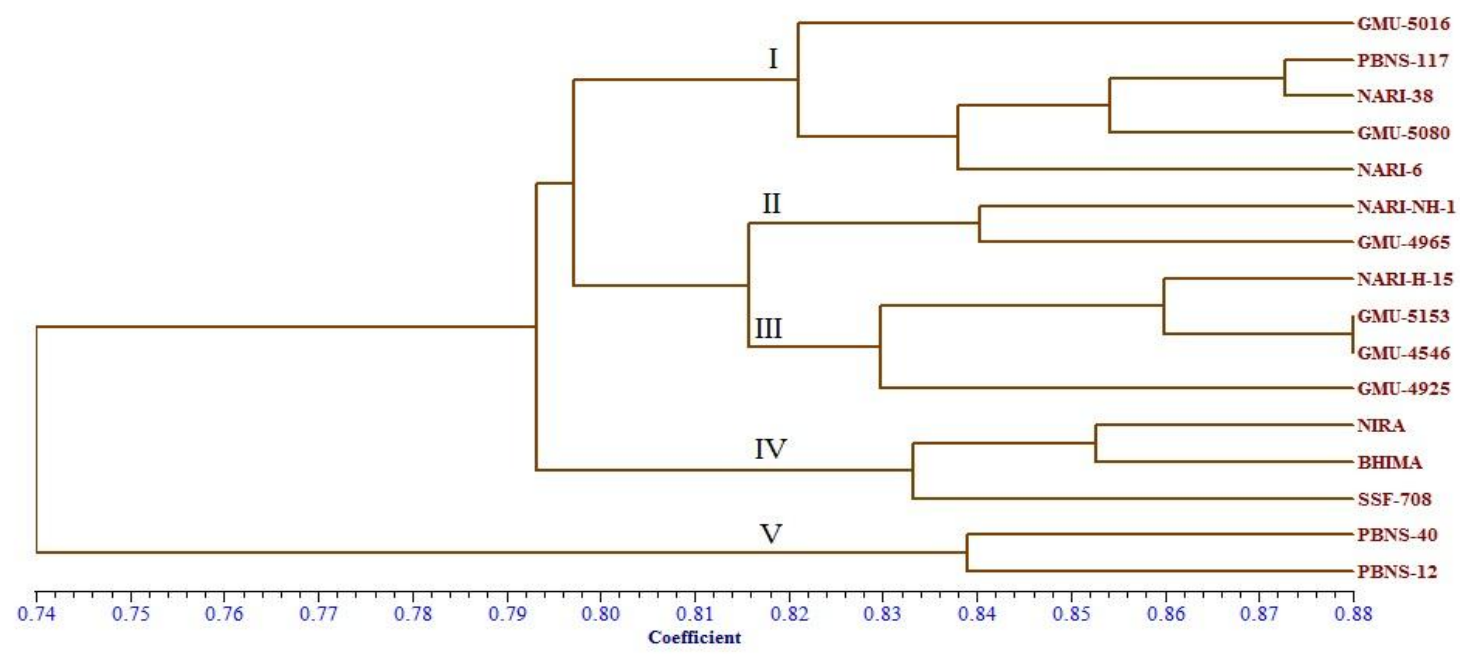

Fig.3 SSR profile of 16 safflower genotypes by primer TA-22

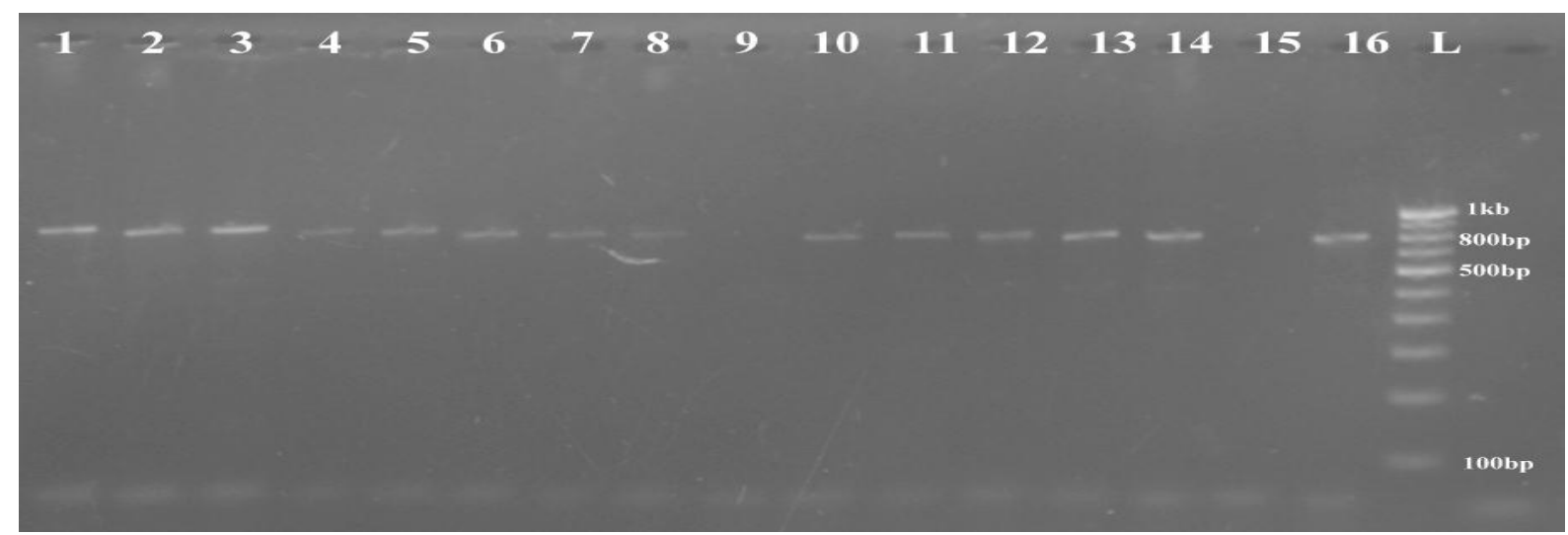

Fig.4 UPGMA based dendrogram showing genetic relationship among 16 safflower genotypes based on SSR analysis

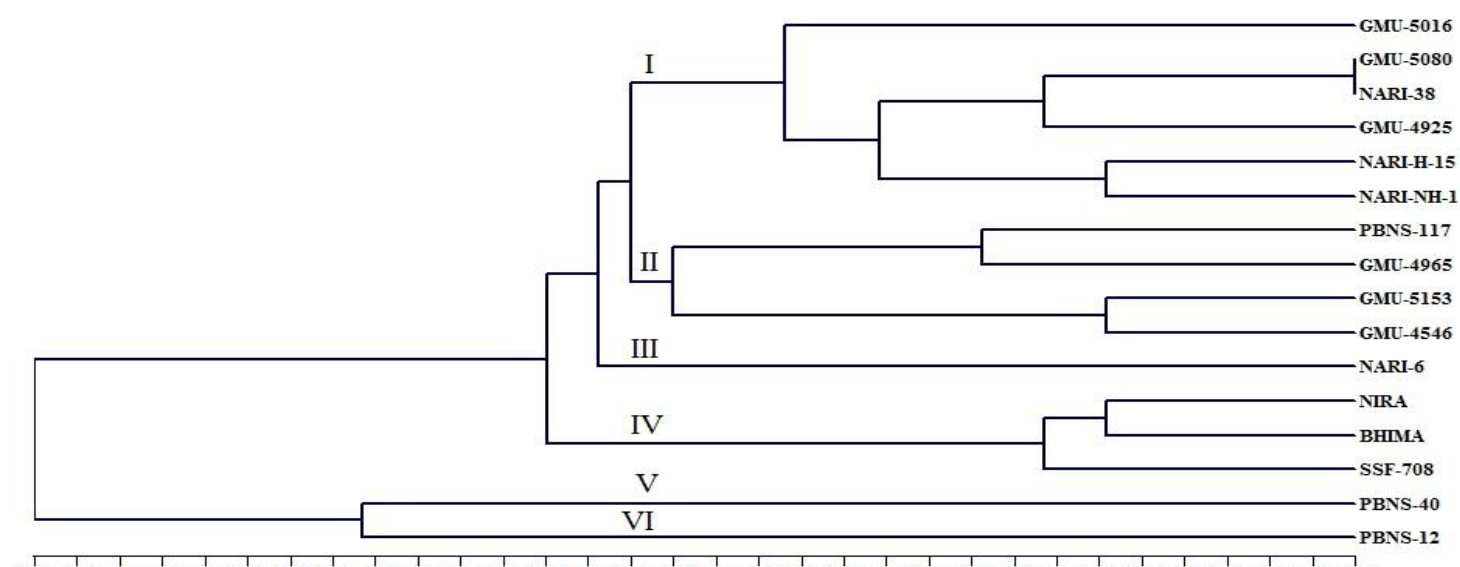

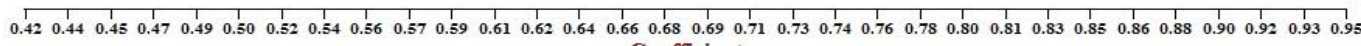
Coefficient 
Cluster V contains 2 susceptible genotypes PBNS-40 and PBNS-12 showing 84\% similarity with each other and $74 \%$ with all other genotypes.

Similarity matrix was calculated by using the data generated by RAPD primers. Maximum similarity (0.87) was noted among GMU5153 and GMU-4546 whereas minimum similarity 0.68 was noted among GMU-5153 and PBNS-40. Average similarity was noted 0.80 (Table 3).Safavi et al., (2010), reported that 20 safflower accessions were separated into main 5 clusters with a cluster distance ranged from 0.27 to 0.85 . Various others studies conducted by different investigators showed similar results such as Khan et al., (2009) and Mahasi et al., (2009). Safavi et al., (2010) and Amini et al., (2008) noticed similarity coefficient in the range of 0.26 to 0.57 and 0.30 to 0.89 , respectively.

\section{SSR analysis}

Seventeen SSR primers yielded a total of 20scorable bands. Total 19 bands were found to be polymorphic with 97.06 percent polymorphism (Table 4). All primers showed maximum $100 \%$ polymorphismexcept primer RGA-H which showed minimum, 50\%polymorphism.Total amplified fragments were 212 with an average 12.47 amplified fragments per primer. Minimum 5 fragments were amplified by primer RGA-D and RGA$\mathrm{E}$ and maximum 25 by primer RGA-G and RGA-H. Primer LG-125 and TA-22 (Fig. 3) amplified 13 and 14 fragments showing PIC 0.81 and 0.87 respectively. Size of bands amplified by primers on an average ranged between 100-2000bp. The calculated PIC values of these polymorphic primers ranged from 0.12-0.96 with an average of 0.63.Sehgal et al., (2009) revealed 57.6 and $68.0 \%$ polymorphism by using RAPD and SSR primers, respectively, among 111 and 72 genetic loci amplified from the 85 accessions.

\section{Cluster analysis based on SSR data}

The dendrogram obtained using SSR data grouped safflower genotypes into six clusters. Cluster I contained maximum (6) genotypes viz., GMU-5016, GMU-5080, NARI-38, GMU-4925, NARI-H-15and NARI-NH-1 all are resistant to Fusarium wilt with $72 \%$ similarity. Genotypes GMU-5080 and NARI38 showed maximum similarity, 95\%. Cluster II comprised of 4 genotypes viz.,PBNS-117, GMU-4965, GMU-5153 and GMU-4546 at $68 \%$ similarity value (Fig. 3). Cluster III contains only 1 resistant genotype NARI-6 showing $64 \%$ similarity with genotypes clustered in cluster I and II. All 5 susceptible genotypes clustered separately in 3 main clusters IV, V and VI. Cluster IV contains 3 susceptible genotypes viz., NIRA, BHIMA and SSF-708 sharing 82\% similarity with each other. Cluster V and VI contains 1 susceptible genotypeeach PBNS-40 and PBNS-12 respectively, showing 55\% similarity with each other and $42 \%$ with all other genotypes.

Similarity matrix was calculated by using the data of SSR primers. Maximum similarity 0.95 was noted among GMU-5080 and NARI38. Minimum similarity 0.20 was noted among NARI-38 and PBNS-40. An average similarity value was 0.63 (Table 3 ). Our result are in accordance with Betha et al., (2015) they characterized 148 safflower accessions for genetic diversityusing 44 simple sequence repeat (SSR). According to them SSR allelic variation was low as indicated by average number of alleles (3.6) per locus and polymorphism information content (0.28) and cluster analysis (neighbour-joining tree) revealed five major genotypic groups. Similarly, Chapman et al., (2010) reported that across 76 accessions of Carthamus tinctorius, the 24 EST-SSR loci amplified between 3 and 15 alleles per locus 
(mean 7.5), expected heterozygosity ranged from 0.10 to 0.84 (mean 0.44 ) and separated in 5 main clusters.

\section{Acknowledgement}

The authors are grateful to the Department of Biotechnology, Government of India, New Delhi, for providing financial support for present study.

\section{References}

Amini, F., Saeidi, G. and Arzani, A. 2008.Study of genetic diversity in Safflower genotypes using agromorphological traits and RAPD markers.Euphytica.163:21-30.

Barati, M. and Arzani, A. 2012.Genetic diversity revealed by EST-SSR markers in cultivated and wild safflower.Biochem. Syst. Ecol.44:117-123.

Betha, U., Mukta, N., Palchamy, K. and Varaprasad, K. S. 2015.Genetic diversity of safflower (Carthamus tinctorius L.) germplasm as revealed by SSR markers. Plant Genetic Resources. DOI: 10.1017/S1479262115000295.

Chapman, M. A., Hvala, J., Strever, J., Matvienko, M., Kozik, A., Michelmore, R. W., Tang, S. H., Kapp, S. J. and Burke, J. M. 2009.Development, polymorphism and cross-taxon utility of EST-SSR markers from safflower (Carthamus tinctorius L.). Theor. Appl. Genet.120:85-91.

Chapman, M. A., Hvala, J., Strever, J. and Burke J. M. 2010.Population Genetic Analysis of Safflower (Carthamus tinctorius; Asteraceae) Reveals A Near Eastern Origin and Five Centers of Diversity. American J. Bot.97(5): 831840.

Dajue, L. and Mundel H. H. 1996.Safflower (Carthamus tinctorius L.) promoting the conservation and use of underutilized and neglected crops 7 . Institute of Plant
Genetics and crop Plant Research, Gatersleben/ International Plant Genetic Resources Institute. Rome, Italy.

Golkar, P., Arzani, A., Rezaei, A. M. 2011. Genetic variation in safflower (Carthamus tinctorious L.) for seed quality-related traits and inter-simple sequence repeat (ISSR) markers.Int. J. Mol. Sci.12: 2664-2677.

Hamdan, Y. A. S., Garcia-Moreno, M. J., Redondo-Nevado, J., Velasco, L. and Perez-Vich, B. 2011.Development and characterization of genomic microsatellite markers in safflower (Carthamus tinctorius L.). Plant Breed.130: 237-241.

Khan, M. A., Witzke-Ehbrecht, S. V., Maass, B. L. and Becker, H. C. 2009.Relationships among different geographical groups, agro morphology, fatty acid composition and RAPD marker diversity in safflower (Carthamus tinctorius L.). Genet. Resour. Crop Evol.56: 19-30.

Kumari, S., Munot, J., Joshi, A., Saharan, V. and Rajamani, G. 2013.Characterization of safflower Carthamus tinctorius L. genotypes through SSR analysis. Online J. Biosci. Inf. 5: 407-419.

Mahasi, M. J., Wachira, F. N., Pathak, R. S. and Riungu, T. C. 2009.Genetic polymorphism in exotic safflower (Carthamus tinctorius L.) using RAPD markers. J. Plant Breed Crop Sci.1: 8-12.

Mayerhofer, R., Archibald, C., Bowles, V. and Good, A. G. 2009.Development of molecular markers and linkage maps for the Carthamus species $C$. tinctorius and C. oxyacanthus.NRC Research Press.53: 266-276.

McPherson, M. A., Good, A. G., Topinka, A. K. C. and Hall, L. M. 2004.Theoretical hybridization potential of transgenic safflower (Carthamus tinctorius L.) with weedy relatives in the New World. Can. J. Plant Sci.84: 923-934. 
Nabloussi, A and Boujghagh, M. 2006. Safflower breeding in Morocco: history and current situation. Sesame Safflower Newsl.21: 84-87.

Ravikumar, R. L., Roopa, V. K., Soregaon, C. D. and Satish, D. 2008. Molecular Diversity in Carthamus species and development of inter-specific mapping population toward development of the first molecular map in safflower. Paper presented at the 7th international safflower conference, Waga Wagga, Australia, 3-9 Nov. 2008.

Rohlf, F. J. 2000.NTSYS-pc Numerical Taxonomy System, ver. 2.1 Exeter Publishing Ltd. Setauket, New York.

Safavi, S. A., Pourdad, S. S., Taeb, M. and Khosroshahli, M. 2010.Assessment of genetic variation among safflower (Carthamus tinctorius L.) accessions using agro-morphological traits and molecular markers. J. Food Agri. Enviro. 8: $616-625$.

Saghai-Maroof, M. A., Soliman, K. M., Jorgensen, R. A. and Allard, R. W. 1984. Ribosomal DNA spacer-length polymorphisms in barley: Mendelian 20 inheritance, chromosomal location, and population dynamics. Proc. Natl. Acad Sci. USA. 81: 8014-8018.

Sehgal, D. and Raina, S. 2005.Genotyping safflower (Carthamus tinctorius L.) cultivars by DNA fingerprints. Euphytica. 146(1): 67-76.

Sehgal, D., Rajpal, V. R., Raina, S. N., Sasanuma, T., Sasakuma, T., Sehgal, D., Rajpal, V. R. and Raina S. N.
2009.Assaying polymorphism at DNA level for genetic diversity diagnostics of the safflower (Carthamus tinctorius L.) world germplasm resources.Genetica.135:457. doi:10.1007/s10709-008-9292-4.

Souframanien, J. and Gopalakrishna, T. 2004.A comparative analysis of genetic diversity in blackgram genotypes using RAPD and ISSR markers.Theor. Appl. Genet. 109: 1687-1693.

Sujatha, M. 2008.Biotechnological interventions for genetic improvement of safflower. Paper presented at the 7th international safflower conference, WagaWagga, Australia, 3-9.

Velasco, L. and Fernandez-Martınez, J. M. 2004.Registration of CR-34 and CR-81 safflower germplasms with increased tocopherol. Crop Sci. 44: 2278.

Xu, Y., Kang, Z.L. and Thomson, M. J. 2012. Molecular breeding in plants: moving into the mainstream. Mol. Breed. 29: 831-832.

Yang, Y. X., Wu, W., Zheng, Y. L., Chen, L., Liu, R. J. and Huang, C. Y. 2007. Genetic diversity and relationships among safflower (Carthamus tinctorius L.) analyzed by inter-simple sequence repeats (ISSRs). Genet Resour Crop Evol.54:1043-1051.

Zhang, L., Huang, B. B., Kai, G. Y. and Guo, M. L. 2006.Analysis of intra-specific variation of Chinese Carthamus tinctorius L. using AFLP marker. Acta Pharm Sin.41:91-96.

\section{How to cite this article:}

Shende, S.S. and Waghmare, D.H. 2017. Molecular Characterization of Fusarium Wilt Resistant and Susceptible Safflower (Carthamus tinctorius L.) Genotypes. Int.J.Curr.Microbiol.App.Sci. 6(9): 3567-3584. doi: https://doi.org/10.20546/ijcmas.2017.609.439 